\title{
Validation of the Shuttle Radar Topography Mission Height Data
}

\author{
Charles G. Brown, Jr., Member, IEEE, Kamal Sarabandi, Fellow, IEEE, and Leland E. Pierce, Senior Member, IEEE
}

\begin{abstract}
The Shuttle Radar Topography Mission (SRTM) provided data for detailed topographical maps of about $80 \%$ of the Earth's land surface. SRTM consisted of single-pass C- and $\mathrm{X}$-band interferometric synthetic aperture radars (INSARs). In order to utilize SRTM data in remote sensing applications the data must be calibrated and validated. This paper presents The University of Michigan's SRTM calibration and validation campaign and our results using recently acquired C-band SRTM data of our calibration sites. An array of calibration targets was deployed with the intention of determining the accuracy of INSAR-derived digital elevation maps. The array spanned one of the $X$-band swaths and stretched from Toledo, OH to Lansing, MI. Passive and active targets were used. The passive targets included trihedrals and tophats. The locations in latitude, longitude, and elevation of the point targets were determined using differential GPS. We also acquired U.S. Geological Survey (USGS) digital elevation models (DEMs) to use in the calibration and validation work. The SRTM data used in this study are both Principal Investigator Processor (PI) data, which are not the refined final data product, and the ground data processing system (GDPS) data, which are a more refined data product. We report that both datasets for southeastern Michigan exceed the SRTM mission specifications for absolute and relative height errors for our point targets. A more extensive analysis of the SRTM GDPS data indicates that it meets the absolute and relative accuracy requirements even for bare surface areas. In addition, we validate the PI height error files, which are used to provide a statistical characterization of the difference between the SRTM GDPS and USGS DEM heights. The statistical characterization of the GDPS-USGS difference is of interest in forest parameter retrieval algorithms.
\end{abstract}

Index Terms-Digital elevation model (DEM), Shuttle Radar Topography Mission, validation.

\section{INTRODUCTION}

$\mathbf{T}$ HE Shuttle Radar Topography Mission (SRTM) was launched aboard the Space Shuttle Endeavour on February 11,2000 . SRTM consisted of single-pass $\mathrm{C}$ - and X-band interferometric synthetic aperture radars. However, in this work we focus on the C-band instrument, since processed data for the U.S. is not yet available from the X-band instrument. During its 11-day mission, SRTM recorded terabytes of data from which

Manuscript received September 30, 2002; revised November 23, 2004. This work was performed at the University of Michigan and supported by the National Aeronautics and Space Administration under Grant NAG5-8930, or otherwise outside of Lawrence Livermore National Laboratory, and published under the auspices of the U.S. Department of Energy by the University of California, Lawrence Livermore National Laboratory under Contract W-7405-Eng-48.

C. G. Brown, Jr. is with the Lawrence Livermore National Laboratory, Livermore, CA 94550 USA (e-mail: brown207@1lnl.gov).

K. Sarabandi and L. E. Pierce are with the Radiation Laboratory, Department of Electrical and Computer Engineering, University of Michigan, Ann Arbor, MI 48109 USA.

Digital Object Identifier 10.1109/TGRS.2005.851789 the first nearly global, high-accuracy topographical map of the Earth from $60^{\circ} \mathrm{N}$ to $56^{\circ} \mathrm{S}$ latitude is being derived. More than 95\% of that targeted area was mapped at least twice to reduce interferometric height errors. When it is completed, the SRTM topographical map will provide coverage of about $80 \%$ of the Earth's surface in a globally consistent manner, with $90 \%(1.6$ standard deviations) absolute and relative height errors less than 16 and $10 \mathrm{~m}$, respectively [1], [2].

The current processed C-band SRTM dataset consists of two types of data: Principal Investigator Processor (PI) data and ground data processing system (GDPS) data. According to [3] and [4], there are several main differences between the datasets.

- The PI dataset includes more information than the GDPS. The GDPS dataset includes only DEMs, while the PI dataset includes power images, incidence angle files, polarizations files, and height error files.

- The PI data may contain residual offsets and tilts, since the PI data takes generally do not include coastlines, which are used in the GDPS data for absolute height calibration, and since the PI data do not use the continental-scale block adjustment.

- The PI data heights are relative to the WGS84 ellipsoid, while the GDPS data are referenced to the WGS84 geoid.

Data from SRTM will find application in a wide variety of military, industrial, and scientific endeavors. All of these applications, including remote sensing of forested areas, require accurately calibrated and validated data. Geodesists from the National Imagery and Mapping Agency (NIMA) and scientists from the Jet Propulsion Laboratory (JPL) have the primary responsibility for the global calibration and validation of SRTM data. Together, they have established over $70000 \mathrm{~km}$ of survey lines, in addition to placing accurately located corner reflectors [1]. JPL scientists have made detailed in-orbit measurements of radar system parameters that are critical to the height map generation [5]. Additionally, ocean data takes, for which the topography is known to the required level of accuracy, are used in calibration and validation [6].

Supplementing the primary calibration and validation efforts of NIMA and JPL are the local campaigns of various research groups. One such group in India deployed corner reflectors and measured their locations in support of a national campaign to use SRTM data in studies of earthquakes, landslides, land subsidence, hydrology, and electromagnetic modeling of vegetation [7]. They also intend to use their corner reflector information to assess the quality of the SRTM data [7].

The University of Michigan also executed a calibration and validation campaign for SRTM during the SRTM overflights [8]. Our efforts were aimed at calibrating and validating the SRTM 


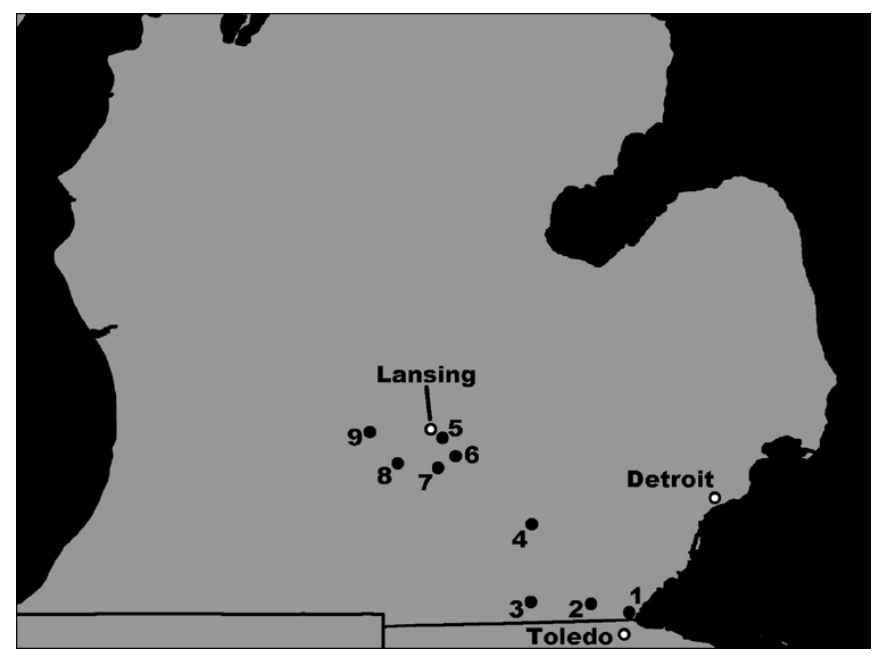

Fig. 1. Point target array. Nine SRTM calibration sites in southeastern Michigan were chosen for point target deployment. Eight of the sites were large, open fields. The remaining site, site 4, featured the highest hill in Washtenaw County. The state boundary map in this figure was created from National Atlas state boundaries [24].

data for the southeastern Michigan area so that we could use it in studies of forest parameter retrieval. Accordingly, we placed a total of 30 point targets in nine sites stretching from north of Toledo to west of Lansing and oriented them to the radar boresight for the four SRTM passes over our sites. During this campaign, the coordinates of the targets were measured using real-time kinematic differential GPS. We also acquired U.S. Geological Survey (USGS) digital elevation models (DEMs) to use in the calibration and validation work.

Careful analysis of the data shows that both SRTM datasets for southeastern Michigan exceed the mission specifications for absolute and relative height errors. First, we briefly describe our calibration and validation array and GPS measurements. Next, we compare the GPS data to the USGS DEMs to check for major blunders in the GPS data. The GPS data and the USGS DEM heights for the point targets are then compared with the PI and GDPS data. Finally, the PI and GDPS data are compared with USGS heights for bare surface areas. We validate the PI data height error files, with respect to the GDPS heights, using the bare surface areas. An earlier version of this work is in [9].

\section{CALIBRATION AND VALIDATION CAMPAIGN}

We recorded point target orientations and positions during SRTM at nine sites stretching from north of Toledo to west of Lansing (see Fig. 1). The sites were selected to cover one of the X-band swaths. The X-band swaths cover Michigan in a lattice-work pattern.

Eight of the sites consisted of large, open fields of winter wheat and soy stubble. The winter wheat and soy stubble fields were chosen as point target sites since the fields are relatively smooth at $\mathrm{C}$ - and $\mathrm{X}$-bands. Thus, their radar return is low compared to the return of the point targets, which is a necessary criterion for a point target site. A total of 30 point targets were distributed in the large, open fields: two polarimetric active radar calibrators (PARCs), seven tophat reflectors, and nine large $(8 \mathrm{ft})$ and 12 small (46 and 48 in) trihedral corner reflectors. One of
TABLE I

SRTM DATA TAKES OVER THE UNIVERSITY OF MiCHIGAN CALIBRATION Sites. Point TARgets Were Aligned to Within $1^{\circ}$ OF THE RADAR BORESIGHT FOR THE FOUR OVERPASSES LISTED IN THIS TABLE. THE ANGLE MEASURES SPECIFY THE ORIENTATION OF THE TARGETS NECESSARY TO POINT THEM INTO THE RADAR BORESIGHT. THE INCIDENCE ANGLE IS MEASURED FROM NADIR

\begin{tabular}{c|r|r|r}
\hline Date & $\begin{array}{r}\text { Time } \\
(\mathrm{EST})\end{array}$ & $\begin{array}{r}\text { Incidence } \\
\text { Angle }\end{array}$ & $\begin{array}{r}\text { Azimuth } \\
\text { Angle }\end{array}$ \\
\hline \hline February 16 & $11: 43 \mathrm{AM}$ & $32^{\circ}$ & $42^{\circ}$ South of East \\
\hline February 16 & $7: 28 \mathrm{PM}$ & $45^{\circ}$ & $46^{\circ}$ South of West \\
\hline February 17 & $11: 29 \mathrm{AM}$ & $44^{\circ}$ & $44^{\circ}$ South of East \\
\hline February 17 & $7: 15 \mathrm{PM}$ & $33^{\circ}$ & $46^{\circ}$ South of West \\
\hline
\end{tabular}

TABLE II

APPROXIMATE RCS OF THE POINT TARGETS USED IN SRTM CALIBRATION

\begin{tabular}{l||l|l}
\hline Target & $\begin{array}{l}\text { Approximate RCS (dBsm) } \\
\text { C-Band }\end{array}$ & X-Band \\
\hline$\overline{\text { PARC }}$ & $57.0 \mathrm{VV}, \mathrm{HH}$ & \\
\hline SAPARC & $51.9 \mathrm{VV}, \mathrm{HH}$ & \\
\hline Tophat & 11.9 to 13.1 & 14.5 to 15.7 \\
\hline Large Trihedral & 46.7 & 51.8 \\
\hline Small Trihedral & $34.0,34.7$ & $39.0,39.8$ \\
\hline
\end{tabular}

the active calibrators was a conventional dual-antenna model, and the other was a single-antenna design (SAPARC) [10]. The seven tophats consisted of cylinders $50.8 \mathrm{~cm}$ high and $50.8 \mathrm{~cm}$ in diameter on circular ground plates $1.52 \mathrm{~m}$ in diameter. One additional site, site 4, contained the highest hill in Washtenaw County, upon which a large trihedral was placed. Another large trihedral was placed in a grassy area near its base for assessing the relative height measurement accuracy of SRTM.

Before each of the four SRTM overpasses, the trihedrals and the PARCs were aligned with the radar boresight to within $1^{\circ}$ in azimuth and elevation. Table I lists the SRTM data takes over the calibration sites and the approximate point target orientation angles. Before all of the overpasses, the tophats were leveled. The approximate radar cross section (RCS) values of the calibration targets are listed in Table II, using wavelengths of 5.6 and $3.122 \mathrm{~cm}$ for C- and X-bands, respectively [11], [12]. The tophats are not visible above the clutter in the C-band images and are not used in the validation process.

The location of each of the point targets was measured using real-time kinematic differential GPS. We placed our base station on National Geodetic Survey (NGS) benchmarks and used the rover to survey stakes upon which the point targets were placed. Since the horizontal and vertical datums of the NGS benchmarks are North American Datum 1983 (NAD83) and North American Vertical Datum 1988 (NAVD88), respectively, postprocessing consists of transforming the NAVD88 orthometric heights for the benchmarks to NAD83 ellipsoidal heights and then using the differential GPS vector with the benchmark as the origin to establish the position of the targets. We do not transform the horizontal datum. Also, no distinction is made at this point between the NAD83 datum and the World Geodetic System 1984 (WGS84) datum, as the two are practically identical for absolute positioning on the order of a meter [13], [14], and the relative height differences are completely negligible for our study area. Later, we will discuss the effects introduced by the differences between WGS84 and NAD83. For the 
TABLE III

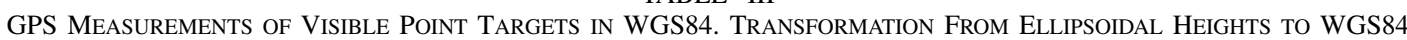
Geoid Heights Is Performed Using the GeOgRaphic Translator [19]

\begin{tabular}{|c|c|c|c|c|c|c|}
\hline Site & Target & Description & Latitude & Longitude & $\begin{array}{l}\text { Ellipsoidal } \\
\text { Height (m) }\end{array}$ & $\begin{array}{l}\text { Geoid } \\
\text { Height }(\mathrm{m})\end{array}$ \\
\hline \multirow[t]{3}{*}{1} & C1 & Small Trihedral & $441^{\circ} 46^{\prime} 2.000^{\prime \prime}$ & $83^{\circ} 31^{\prime} 0.000^{\prime \prime}$ & 144.51 & 180.40 \\
\hline & P1 & PARC & $41^{\circ} 46^{\prime} 13.333^{\prime \prime}$ & $83^{\circ} 30^{\prime} 42.424^{\prime \prime}$ & 144.30 & 180.18 \\
\hline & S1 & SAPARC & $41^{\circ} 46^{\prime} 8.632^{\prime \prime}$ & $83^{\circ} 30^{\prime} 56.952^{\prime \prime}$ & 144.44 & 180.32 \\
\hline \multirow[t]{3}{*}{2} & $\mathrm{C} 2$ & Small Trihedral & $41^{\circ} 49^{\prime} 9.087^{\prime \prime}$ & $83^{\circ} 43^{\prime} 12.231^{\prime \prime}$ & 172.61 & 208.27 \\
\hline & C3 & Small Trihedral & $41^{\circ} 49^{\prime} 12.593^{\prime \prime}$ & $83^{\circ} 42^{\prime} 58.546^{\prime \prime}$ & 172.43 & 208.10 \\
\hline & L1 & Large Trihedral & $41^{\circ} 49^{\prime} 10.731^{\prime \prime}$ & $83^{\circ} 43^{\prime} 5.356^{\prime \prime}$ & 172.42 & 208.09 \\
\hline \multirow[t]{4}{*}{$\overline{3}$} & $\mathrm{C} 4$ & Small Trihedral & $41^{\circ} 49^{\prime} 19.282^{\prime \prime}$ & $84^{\circ} 1^{\prime} 51.479^{\prime \prime}$ & 207.20 & 242.63 \\
\hline & $\mathrm{C} 5$ & Small Trihedral & $41^{\circ} 49^{\prime} 12.626^{\prime \prime}$ & $84^{\circ} 1^{\prime} 51.311^{\prime \prime}$ & 204.32 & 239.76 \\
\hline & L2 & Large Trihedral & $41^{\circ} 49^{\prime} 22.611^{\prime \prime}$ & $84^{\circ} 2^{\prime} 7.324^{\prime \prime}$ & 205.32 & 240.75 \\
\hline & L3 & Large Trihedral & $41^{\circ} 49^{\prime} 12.585^{\prime \prime}$ & $84^{\circ} 1^{\prime} 59.766^{\prime \prime}$ & 206.42 & 241.86 \\
\hline \multirow[t]{2}{*}{$\overline{4}$} & $\mathrm{~L} 4$ & Large Trihedral & $42^{\circ} 13^{\prime} 55.321^{\prime \prime}$ & $84^{\circ} 1^{\prime} 40.814^{\prime \prime}$ & 250.15 & 284.81 \\
\hline & L9 & Large Trihedral & $42^{\circ} 13^{\prime} 49.224^{\prime \prime}$ & $84^{\circ} 2^{\prime} 0.550^{\prime \prime}$ & 274.36 & 309.02 \\
\hline 5 & $\mathrm{C} 6$ & Small Trihedral & $42^{\circ} 41^{\prime} 18.846^{\prime \prime}$ & $84^{\circ} 29^{\prime} 37.938^{\prime \prime}$ & 230.19 & 264.23 \\
\hline \multirow[t]{2}{*}{6} & $\mathrm{C} 7$ & Small Trihedral & $42^{\circ} 35^{\prime} 33.060^{\prime \prime}$ & $84^{\circ} 25^{\prime} 28.810^{\prime \prime}$ & 245.76 & 279.92 \\
\hline & L5 & Large Trihedral & $42^{\circ} 35^{\prime} 31.867^{\prime \prime}$ & $84^{\circ} 25^{\prime} 42.202^{\prime \prime}$ & 246.65 & 280.81 \\
\hline \multirow[t]{2}{*}{$\overline{7}$} & $\mathrm{C} 8$ & Small Trihedral & $42^{\circ} 31^{\prime} 50.588^{\prime \prime}$ & $84^{\circ} 31^{\prime} 6.073^{\prime \prime}$ & 263.65 & 297.97 \\
\hline & L6 & Large Trihedral & $42^{\circ} 31^{\prime} 58.309^{\prime \prime}$ & $84^{\circ} 31^{\prime} 10.051^{\prime \prime}$ & 260.40 & 294.72 \\
\hline \multirow[t]{3}{*}{8} & $\mathrm{C} 9$ & Small Trihedral & $42^{\circ} 33^{\prime} 25.811^{\prime \prime}$ & $84^{\circ} 43^{\prime} 44.623^{\prime \prime}$ & 236.11 & 270.51 \\
\hline & C10 & Small Trihedral & $42^{\circ} 33^{\prime} 17.712^{\prime \prime}$ & $84^{\circ} 43^{\prime} 43.157^{\prime \prime}$ & 238.96 & 273.37 \\
\hline & L7 & Large Trihedral & $42^{\circ} 33^{\prime} 13.802^{\prime \prime}$ & $84^{\circ} 43^{\prime} 35.109^{\prime \prime}$ & 236.86 & 271.27 \\
\hline \multirow[t]{3}{*}{$\overline{9}$} & C11 & Small Trihedral & $42^{\circ} 43^{\prime} 5.744^{\prime \prime}$ & $84^{\circ} 52^{\prime} 28.884^{\prime \prime}$ & 238.18 & 272.41 \\
\hline & C12 & Small Trihedral & $42^{\circ} 42^{\prime} 27.595^{\prime \prime}$ & $84^{\circ} 53^{\prime} 21.143^{\prime \prime}$ & 232.27 & 266.51 \\
\hline & L8 & Large Trihedral & $42^{\circ} 43^{\prime} 43.442^{\prime \prime}$ & $84^{\circ} 53^{\prime} 1.962^{\prime \prime}$ & 235.26 & 269.48 \\
\hline
\end{tabular}

same reasons, we do not make a distinction among the various NAD83 datums. See [15] and [16] for a discussion of NAD83 and WGS84 datums. We assume that the particular variety of WGS84 datum employed by SRTM is WGS84(G873).

We use the NGS Tool Kit program GEOID99 [17] to perform the vertical datum shift from NAVD88 orthometric heights to NAD83 ellipsoidal heights, assuming Helmert's projection [18]. Finally, we use the program Geographic Translator [19] from NIMA to convert the NAD83 ellipsoidal heights ( $\approx$ WGS84 ellipsoidal heights) of the individual points to heights above the WGS84 geoid [13]. A complete tabulation of the data, with ellipsoidal and geoid heights, for all of the visible point targets is given in Table III. Absolute position errors in the GPS data are expected to be on the order of a meter, mainly due to NGS benchmark location error; mismatch between the survey stake location and the actual location of the point target phase center; operator error; and datum transformation error. Relative error for points within the same site is expected to be in the decimeter range.

In order to check for major blunders in and roughly to characterize the accuracy of our GPS measurements, we compare the GPS measurements with the corresponding USGS DEM heights. The USGS DEMs used are $1: 24 \mathrm{k}$ DEMs in Universal Transverse Mercator (UTM) projection with 30-m horizontal resolution. The horizontal datum is North American Datum 1927 (NAD27). The vertical datum is National Geodetic Vertical Datum 1929 (NGVD29). First, we use the NGS Tool Kit program NADCON [17] to transform the GPS horizontal coordinates from NAD83 to NAD27. We then find the NGVD29 heights of those points from the USGS DEMs. We convert the NGVD29 heights to NAD83 ellipsoidal heights by using the NGS Tool Kit programs VERTCON and GEOID99 [17]. The difference between the GPS heights and the resulting USGS heights is plotted in Fig. 2(a). The mean of the difference is $-0.3 \mathrm{~m}$ with a standard deviation of $0.8 \mathrm{~m}$. The minimum and maximum values are -2.2 and $1.6 \mathrm{~m}$, respectively. Note the trend in the data as a function of GPS measurement number. The measurements are in the same order as in Table III, with the coordinates generally progressing from the southeast to the northwest. We perform a least squares fit of a plane to the GPS-USGS differences. The resulting fit has an $R^{2}$ value of about 0.3 , which suggests that the observed trend is relatively weak. Indeed, the slopes of the planar fit in latitude and longitude are only -9.3 and 1.6 parts per million (ppm), respectively. Such trends could be due to the USGS DEMs or even the NGS benchmarks used to tie our GPS measurements to the NAD83 datum. Since the majority of our benchmarks are vertical first order or worse, it is reasonable to expect errors greater than 10 ppm [20]. The standard deviation of the GPS-USGS difference after the trend is removed is $0.7 \mathrm{~m}$. These data indicate that there are no major blunders in the GPS measurements, at least on the order of a meter, increasing our confidence in the GPS measurements. Based on the comparisons with the USGS DEMs and on the absolute accuracy estimates in [20], we assume that our GPS measurements have a standard deviation of $1 \mathrm{~m}$ when used for absolute positioning.

A relative positioning accuracy check is performed by comparing the differences between the GPS measurements within a site (GPS differentials) with their corresponding USGS DEM differences (USGS differentials). This accuracy check should be insensitive to absolute height errors caused by offsets between the NGS benchmarks and the USGS DEMs. The standard deviation of the difference between the GPS differentials and the USGS differentials is $1.0 \mathrm{~m}$ with a mean of $0.2 \mathrm{~m}$ [see Fig. 2(b)], suggesting that the standard deviation of our GPS measurements is about $1 \mathrm{~m}$ when used for relative positioning within a site. 


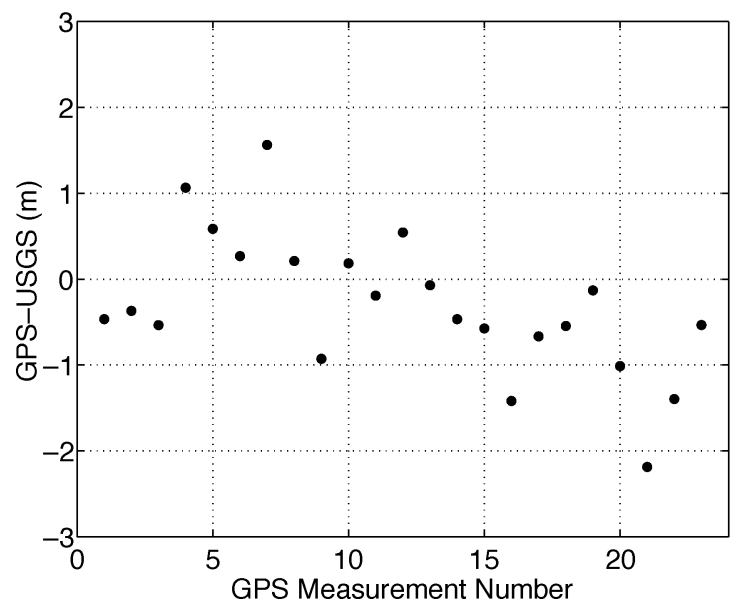

(a)

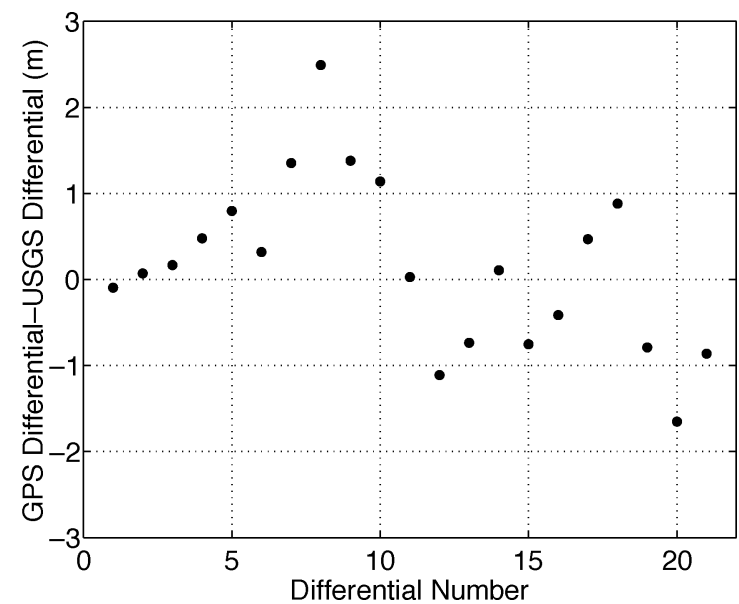

(b)

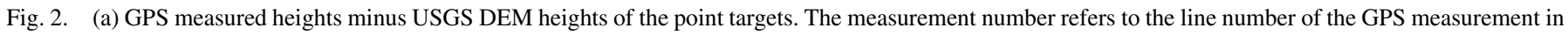

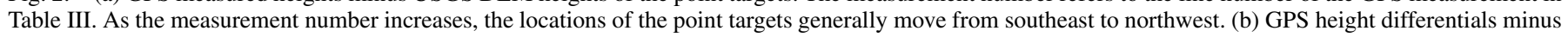
USGS DEM height differentials for the point targets.

Of course, both the absolute and relative accuracies of our GPS measurements are probably better than what is indicated by the comparison with the USGS DEMs, since the USGS DEMs are themselves only approximations of the topography. However, the comparison with the USGS DEMs provides an approximate upper bound on the GPS errors that will be useful in the validation of the SRTM DEMs.

\section{VALIDATION OF THE SRTM DATA: POINT TARGET ARRAY}

In this section, we examine the absolute and relative accuracies of the SRTM data using our GPS measurements and USGS DEMs for our point target array. First, we begin with the absolute height accuracy of the SRTM data using our GPS measurements. Fig. 3 displays the difference between the SRTM PI heights and the GPS measurements and the difference between the SRTM GDPS heights and the GPS measurements. The comparison with SRTM PI data is based on GPS ellipsoidal heights, while the comparison with SRTM GDPS data is based on WGS84 geoid heights. Of particular interest in Fig. 3 are the comparatively large offset (minimum $5.0 \mathrm{~m}$, maximum $13.0 \mathrm{~m}$, and mean $8.7 \mathrm{~m}$ ) and the pronounced trend in the offset of the PI data. A planar least squares fit to the offset yields an $R^{2}$ value of 0.5 , indicating a moderately strong trend. The slopes of the planar fit in latitude and longitude are $-42.8 \mathrm{ppm}$ and $-5.4 \mathrm{ppm}$. The standard deviation of the offsets, after the trend is removed, is $1.7 \mathrm{~m}$. The errors in the GPS measurements are probably not significant enough to produce such a pronounced trend in the SRTM PI data. They are certainly not significant enough to yield offsets in the 5-13-m range. Even with such large offsets, the SRTM PI data meet the absolute height accuracy requirement of $16 \mathrm{~m}$ for the point targets. Refer to Table IV for a summary of the validation results from Sections III and IV.

The SRTM GDPS data are a marked improvement over the SRTM PI data, as is indicated by the small offset and reduced trend in Fig. 3. We ignore the two-standard-deviation outliers, point targets $\mathrm{P} 1$ and $\mathrm{S} 1$ in site 1 , in the analysis of the GDPS data. After removing the outliers, the offset ranges from a minimum of -3.4 to a maximum of $1.1 \mathrm{~m}$, with a mean of

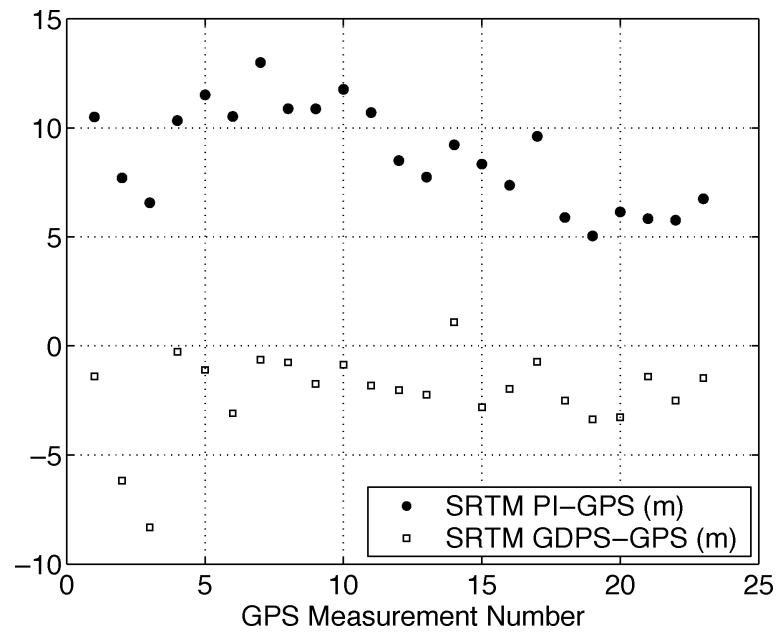

Fig. 3. SRTM PI heights minus GPS measured heights and SRTM GDPS heights minus GPS measured heights of the point targets. See Fig. 2 for the definition of measurement number. Points 2 and 3, P1 and S1 from site 1, are outliers.

TABLE IV

SUMMARY OF SRTM VALIDATION RESULTS FROM SECTIONS III AND IV. THE "TYPE" COLUMN GIVES THE TYPE OF ACCURACY CONSIDERED, ABSOLUTE OR RElative. THE "SRTM DATA" AND “COMPARISON DATA" COLUMNS SPECIFY THE SRTM HEIGHT DATASET EVALUATED AND THE HEIGHT DATA USED AS THE STANDARD IN THE COMPARISON, WHICH IS EITHER OUR GPS MEASUREMENTS OR USGS DEMS

\begin{tabular}{c|c|c|c|c}
\hline Section & Type & SRTM Data & Comparison Data & Accuracy \\
\hline \hline III & Absolute & PI & GPS & 5 to $13 \mathrm{~m}$ \\
\hline III & Absolute & GDPS & GPS & -3.4 to $1.1 \mathrm{~m}$ \\
\hline III & Absolute & PI & USGS & 3.7 to $14.6 \mathrm{~m}$ \\
\hline III & Absolute & GDPS & USGS & -4.3 to $1.1 \mathrm{~m}$ \\
\hline IV & Absolute & GDPS & USGS & $2.0 \mathrm{~m}$ \\
\hline III & Relative & PI & GPS & 1.6 to $1.7 \mathrm{~m}$ \\
\hline III & Relative & GDPS & GPS & 1.1 to $1.3 \mathrm{~m}$ \\
\hline III & Relative & PI & USGS & $2.1 \mathrm{~m}$ \\
\hline III & Relative & GDPS & USGS & $1.9 \mathrm{~m}$ \\
\hline IV & Relative & GDPS & USGS & $3.3 \mathrm{~m}$ \\
\hline
\end{tabular}

$-1.7 \mathrm{~m}$. There is almost no trend in the offsets, since a planar least squares fit yields an $R^{2}$ value of only 0.1 . The standard deviations of the offsets with and without the outliers excluded 


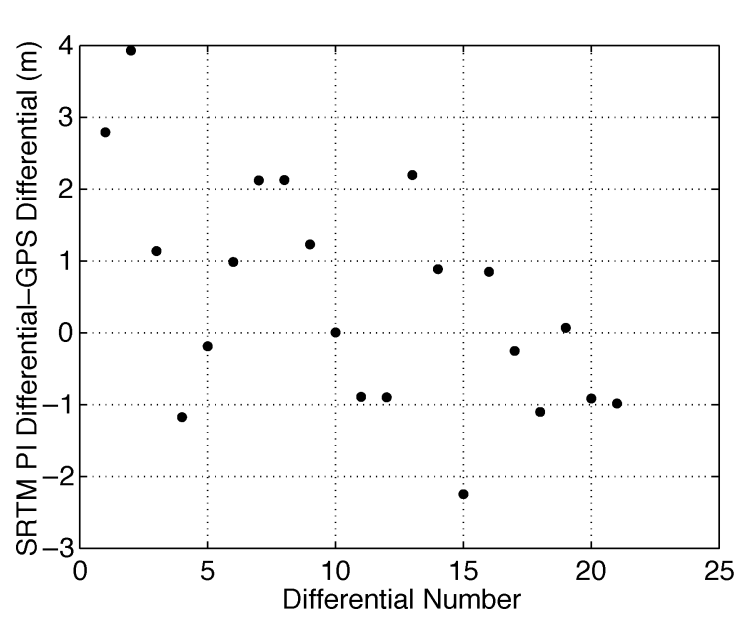

(a)

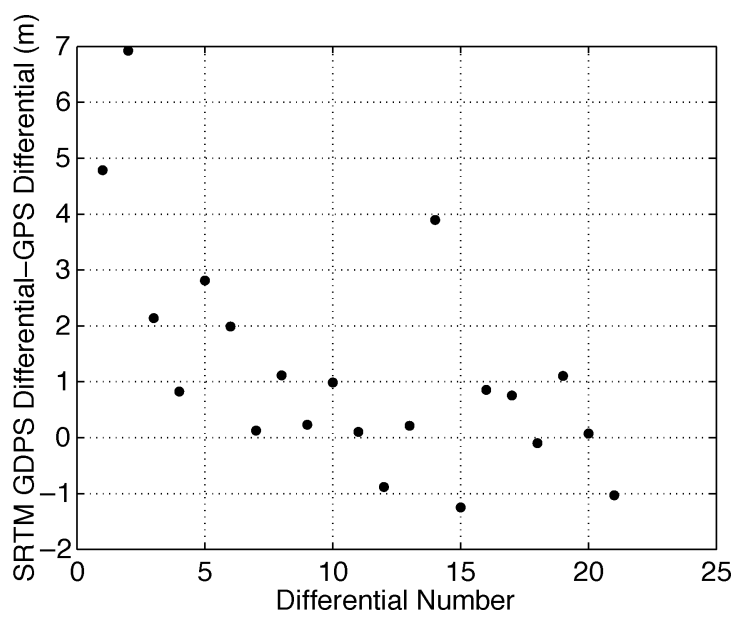

(b)

Fig. 4. (a) SRTM PI height differentials minus GPS height differentials for the point targets. (b) SRTM GDPS height differentials minus GPS height differentials for the point targets. The first three points are from site 1 and are corrupted by the outliers in Fig. 3 .

are 1.1 and $1.9 \mathrm{~m}$, respectively. The mean offset of $-1.7 \mathrm{~m}$ can be explained partially by our assumption that NAD $83 \approx$ WGS84, as explained below.

Our original GPS measurements are in a hybrid reference frame consisting of a mix of NAD83 and WGS84, since we are using differential GPS with the NGS benchmarks as control [21]. In our case, where the distance from the NGS benchmarks to our survey points is always less than about $10 \mathrm{~km}$, we can assume that the datum of our GPS measurements is NAD83 and incur less than a centimeter of error because of this assumption [21]. The horizontal positions of the NGS benchmarks we used are specified in NAD83. The heights of the benchmarks, however, are specified as Helmert orthometric heights [18] in the NAVD88 datum. Recall that we used the NGS Tool Kit program GEOID99 [17] to convert the benchmarks from NAVD88 to NAD83 ellipsoidal heights. For simplicity we assumed NAD83 $\approx$ WGS 84 , and when the Geographic Translator [19] called for WGS84(G873) horizontal coordinates and ellipsoidal heights, we gave it the NAD83 horizontal coordinates and ellipsoidal heights. The impact of this simplification can be quantified using the NGS Tool Kit program HTDP [17], which performs the datum shift between NAD83 and WGS84(G873). The transformation is approximately a constant offset for our sites: WGS84(G873) ellipsoidal heights =NAD83 ellipsoidal heights $1.1 \mathrm{~m}$. So the GPS heights used in Fig. 3 are $1.1 \mathrm{~m}$ too large. Correction for the difference between NAD83 and WGS84(G873) yields a mean offset of $9.8 \mathrm{~m}$ for the PI data and $-0.6 \mathrm{~m}$ for the GDPS data. Even without the offset correction, we can see that the SRTM GDPS data easily meet the absolute height accuracy requirement of $16 \mathrm{~m}$ for the point targets. Also, even with the offset correction, the SRTM PI data still meet the absolute accuracy requirement for our point targets.

The comparison of the GPS measurements with the SRTM PI and GDPS data also provides insight into the relative accuracy of the data. Recall that for the PI and GPS difference, the standard deviation is $1.7 \mathrm{~m}$, and for the GDPS and GPS difference it is $1.1 \mathrm{~m}$. These standard deviations are measures of the relative accuracy of the SRTM data, which is probably on the

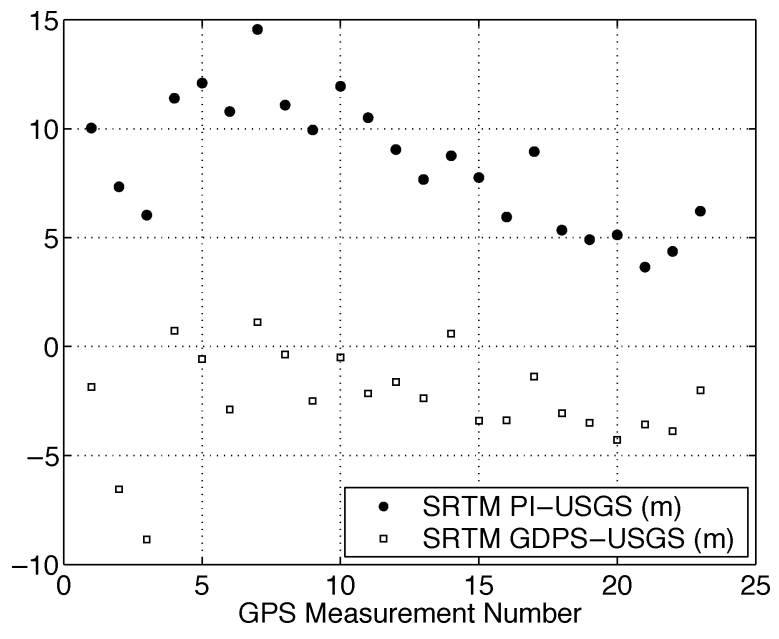

Fig. 5. SRTM PI heights minus USGS heights and SRTM GDPS heights minus USGS heights of the point targets. See Fig. 2 for the definition of measurement number. Points 2 and 3, P1 and S1 from site 1, are outliers.

order of a meter for our point targets. Perhaps a better way to quantify the relative accuracy is by comparing the differences between the SRTM measurements within a site (SRTM differentials) with their corresponding GPS differences (GPS differentials), as we did with the GPS and USGS data. One benefit of this method is that for our relatively small sites absolute errors due to NGS benchmark location, datum transformations, and long-wave SRTM offsets are subtracted out. Fig. 4 displays the differences between the SRTM PI and GDPS differentials and the GPS differentials. The standard deviation of Fig. 4(a) is $1.6 \mathrm{~m}$, while the standard deviation of Fig. 4(b) is $2.0 \mathrm{~m}$. The first three points in Fig. 4(b) are corrupted by the outliers in Fig. 3. When they are removed, the standard deviation of the remaining points in Fig. 4(b) is $1.3 \mathrm{~m}$. Hence, from both the differential method and the previous method using absolute heights, we can conclude that the relative height errors for our point targets is about $1.6-1.7 \mathrm{~m}$ for the PI data and about $1.1-1.3 \mathrm{~m}$ for the GDPS data.

Comparison of the SRTM PI and GDPS data with the USGS DEM heights for the point targets yields similar results. Fig. 5 


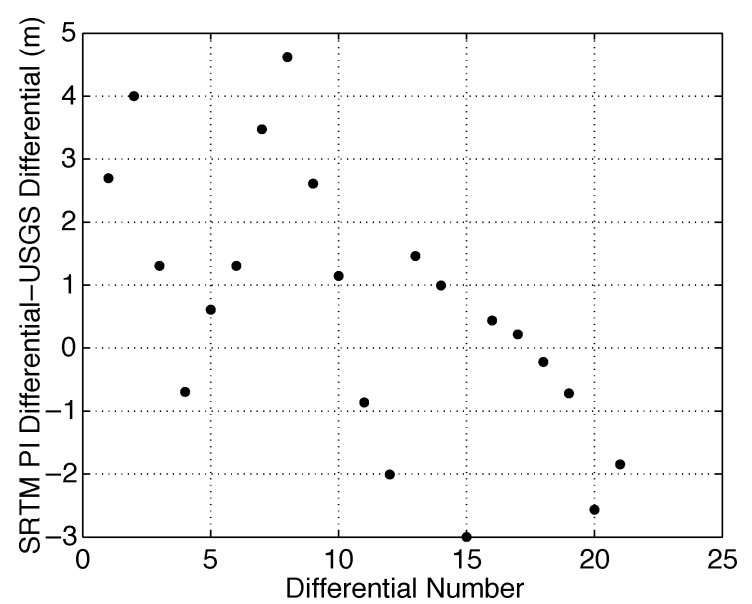

(a)

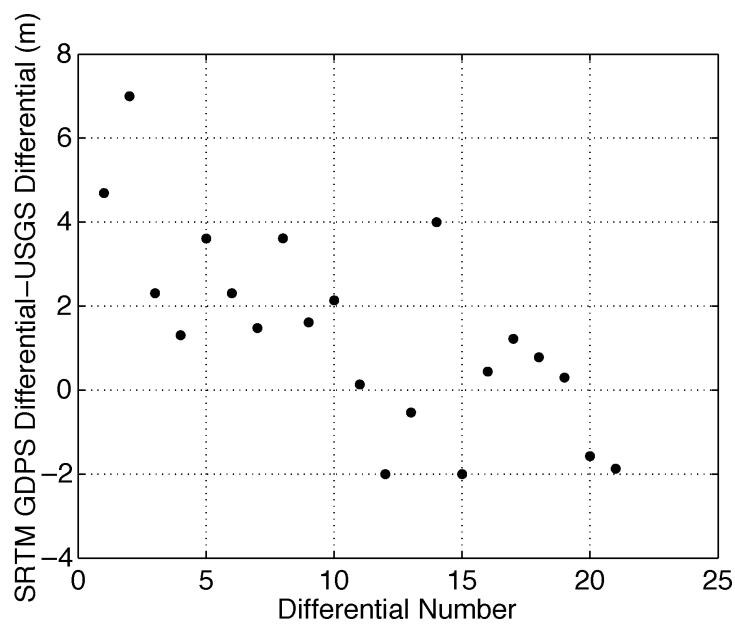

(b)

Fig. 6. (a) SRTM PI height differentials minus USGS height differentials for the point targets. (b) SRTM GDPS height differentials minus USGS height differentials for the point targets. The first three points are from site 1 and are corrupted by the outliers in Fig. 5 .

plots the differences between the SRTM and USGS heights. As with the GPS data, the difference between the SRTM PI and USGS heights is performed on the ellipsoidal heights. Geographic Translator [19] is used to convert ellipsoidal heights to heights above the WGS84 geoid [13] for the GDPS minus USGS difference. In Fig. 5 we see a large offset in the PI data similar to that in Fig. 3. The minimum, maximum, and mean are 3.7, 14.6, and $8.4 \mathrm{~m}$. Again, there is a pronounced trend in the offset. A planar least squares fit to the offset yields an $R^{2}$ value of 0.5 , indicating a moderately strong trend. The slopes of the planar fit in latitude and longitude are -52.1 and $-3.8 \mathrm{ppm}$, respectively. The standard deviation of the offsets, after the trend is removed, is $2.0 \mathrm{~m}$.

In Fig. 5, as in Fig. 3, we see the improvement of the SRTM GDPS data over the SRTM PI data. The offset is smaller and the trend is reduced. Ignoring point targets $\mathrm{P} 1$ and $\mathrm{S} 1$ in site 1 as before, even though P1 is no longer a two-standard-deviation outlier, yields an offset range from a minimum of $-4.3 \mathrm{~m}$ to a maximum of $1.1 \mathrm{~m}$, with a mean of $-1.9 \mathrm{~m}$. There is almost no trend in the offsets, since a planar least squares fit yields an $R^{2}$ value of only 0.1 . The standard deviations of the offsets with and without the outliers excluded are 1.6 and $2.3 \mathrm{~m}$, respectively. Most of the mean offset of $-1.9 \mathrm{~m}$ can be accounted for as with the mean offset in the SRTM GDPS minus GPS difference.

As with the GDPS data, we can use the USGS data to extract information about the relative accuracies of the SRTM PI and GDPS data. Recall that for the PI and USGS difference, the standard deviation was $2.0 \mathrm{~m}$, and for the GDPS and USGS difference it was $1.6 \mathrm{~m}$. The relative accuracies obtained by the differential method are 2.1 and $2.4 \mathrm{~m}$ (1.9 m ignoring site 1), for PI and GDPS, respectively. Fig. 6 displays the differences between the SRTM PI and GDPS differentials and the USGS differentials. The relative accuracies obtained using the USGS data are somewhat worse than those obtained using the GPS data, perhaps because the USGS DEMs are less accurate than the GPS measurements.

Although the specific goal of the data collected for this paper is to validate the SRTM height data, it is also possible to use our GPS measurements for a horizontal accuracy assessment. We perform a preliminary assessment using the SRTM PI power data and the GPS measurements from site 8. Site 8 is chosen because it is very flat and contains a relatively large number of visible point targets. Since the GDPS dataset we have access to does not have power data, we are confined to the SRTM PI data for horizontal accuracy assessment. We measure the distance from the center of the brightest pixel in the power image to the GPS location for each visible point target for each overpass. The minimum distance is $6 \mathrm{~m}$, and the maximum distance is $25 \mathrm{~m}$. From these measurements, we can conclude that the horizontal accuracy of the SRTM PI data is better than $30 \mathrm{~m}$ for site 8, although a more exhaustive study involving other sites would be needed to generalize that statement.

\section{VALidATION OF THE SRTM Data: BARE SURface AREAS}

The results reported so far in this paper pertain to validation using the SRTM height data for our point target array. It is well known that the accuracy of interferometric SAR (INSAR) height increases as the signal-to-noise ratio (SNR) increases [22], and point targets in interferometric INSAR images have very high SNR. Thus, the previous validation perhaps is more of a characterization of the height inaccuracies due to INSAR geometry errors (e.g., see [5]). In order to validate the SRTM data in the presence of all the noise sources, except vegetation decorrelation [23], we now proceed to validate using bare surface areas. We will also demonstrate a method for predicting absolute and relative height error using the SRTM PI height error files and the USGS DEM error information.

First, we construct a mosaic of the SRTM PI and GDPS data for southeastern Michigan. Fig. 7 depicts the mosaic for the PI data overlayed on a map of Michigan. The GDPS mosaic is similar, except that it excludes the upper right $1^{\circ}$ by $1^{\circ}$ tile since it contains a portion of Canada. We also compose a mosaic of the Michigan USGS DEMs covering the Michigan portion of the SRTM mosaic. Fig. 8 displays that mosaic. The grid pattern results from the method we used to reproject the DEMs. The DEMs are originally in the UTM projection and in the NAD27 datum with NGVD29 heights. We use PCI software 


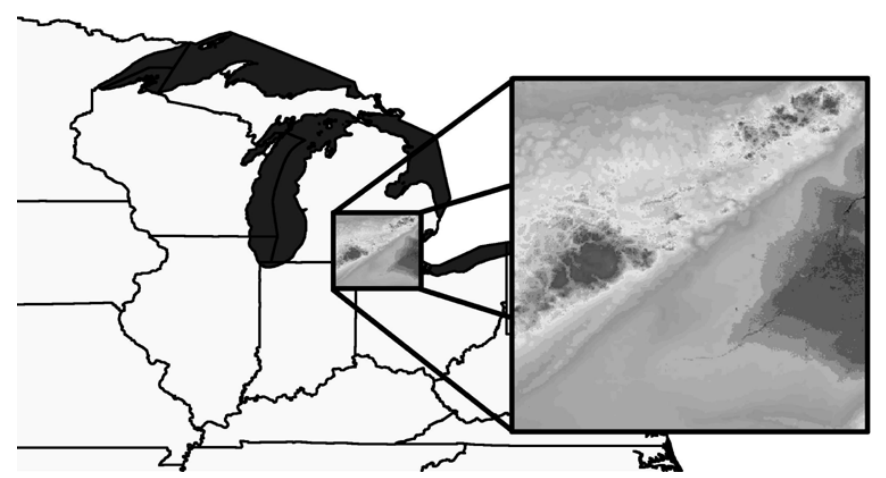

Fig. 7. Mosaic of SRTM PI height data along with map of the Midwest for perspective. The state boundary map in this figure was created from National Atlas state boundaries [24].

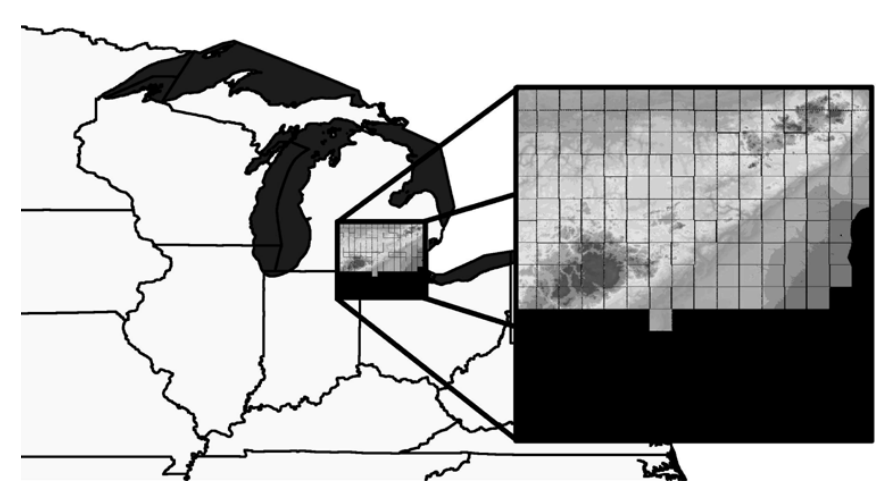

Fig. 8. Mosaic of USGS DEM height data along with map of the Midwest for perspective. The state boundary map in this figure was created from National Atlas state boundaries [24].

(http://www.pcigeomatics.com/) to reproject from UTM to latitude/longitude. The reprojection loses some information near the borders of the DEM quadrangles so that the resulting mosaic has a grid pattern of zero-height areas. We avoid these in the analysis. We also use PCI software to transform from NAD27 to NAD83 horizontal coordinates, since the method that it uses is based on the NGS Tool Kit program NADCON [17]. So, in summary, we have an SRTM PI mosaic in WGS84 with WGS84 ellipsoidal heights, SRTM GDPS mosaic in WGS84 with WGS84 geoid heights, and a USGS DEM mosaic in NAD83 with NGVD29 heights. As stated earlier, NAD83 and WGS84 are quite similar, and at the 30-m horizontal resolution of SRTM the differences should be negligible. We compare only the SRTM GDPS with the USGS DEMs, since the GDPS is closer to the final SRTM product.

Our goal is to collect a set of collocated data points from the SRTM GDPS mosaic and the USGS DEM mosaic for bare surface areas. Using these areas, we demonstrate a method of predicting absolute and relative error from USGS DEM and SRTM PI height error information. In order to select bare surface areas, we employ the National Land Cover Dataset (NLCD) (http://landcover.usgs.gov/natllandcover.html) for the area of our mosaics. We step through a grid of points in the NLCD and determine if the pixel is bare surface. If it is bare surface according to the NLCD and if it is not in any of the zero-height areas in the USGS DEM mosaic, then we collect SRTM GDPS and USGS DEM heights as well as SRTM PI

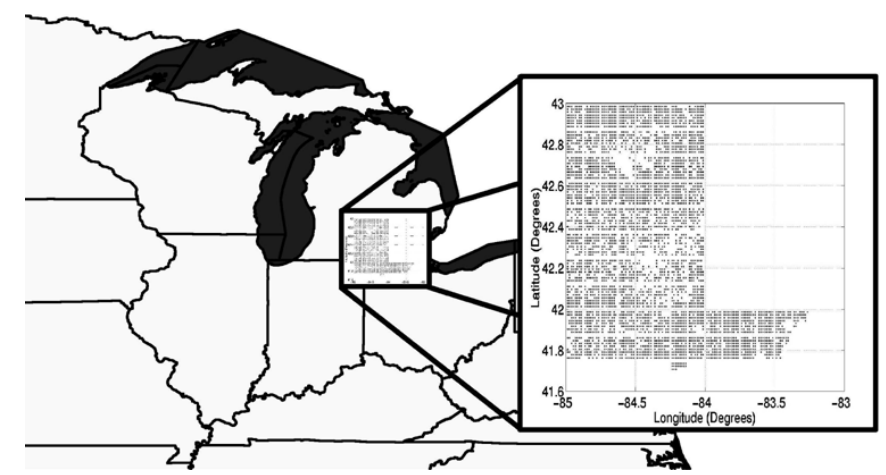

Fig. 9. Map of the 4163 bare surface points identified using NLCD that are not in any of the zero-height areas in the USGS DEM mosaic. Observe the blank upper right area, due to the missing upper right $1^{\circ}$ by $1^{\circ}$ GDPS tile that contains a portion of Canada. The state boundary map in this figure was created from National Atlas state boundaries [24].

and USGS error values for that point. We collected 4163 bare surface points. See Fig. 9.

For the analysis of absolute height errors and the first analysis of relative height errors, we employ the absolute method used before in this paper with the GDPS data and USGS DEMs. We compute the GDPS-USGS height difference for each of the 4163 points in the set. Since NGVD29 and the WGS84 geoid are within about a meter of each other over our area, and since the HTDP [17] height correction is constant within about $0.5 \mathrm{~m}$ across our area, we can compare the SRTM GDPS and USGS DEM heights without further transformation beyond what we already listed.

In order to predict the absolute error, which here is the standard deviation of the GDPS-USGS difference, we formulate the theoretical value. If we denote the SRTM GDPS height of any point as $h_{\text {GDPS }}$ and the corresponding USGS DEM height as $h_{\text {USGS }}$, then the height difference is $\Delta h_{\mathrm{GDPS}-\mathrm{USGS}}=h_{\mathrm{GDPS}}-h_{\mathrm{USGS}}$. Let us view the noise on the heights of the GDPS and USGS DEM points as normally distributed random variables, which is an appropriate assumption because of the relatively large amount of averaging that occurs to generate a single SRTM GDPS pixel. Further assume that they are independent. Under these assumptions, the standard deviation is

$$
\sigma_{\Delta h_{\mathrm{GDPS}-\mathrm{USGS}}}=\sqrt{\sigma_{h_{\mathrm{GDPS}}}^{2}+\sigma_{h_{\mathrm{USGS}}}^{2}}
$$

where $\sigma_{h_{\mathrm{GDPS}}}$ and $\sigma_{h_{\mathrm{USGS}}}$ are the standard deviations of the noise on the GDPS and USGS heights. The standard deviation of the noise on the GDPS heights is obtained from the PI height error files for each point. The standard deviation of the noise on the USGS heights is obtained from the metadata for each USGS quadrangle and is the same for all points within that quadrangle.

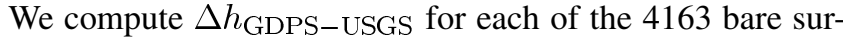
face points. Also, for each value of $\Delta h_{\text {GDPS-USGS }}$ we compute the predicted standard deviation $\sigma_{\Delta h_{\mathrm{GDPS}-U S G S}}$ using (1). We bin the values of $\sigma_{\Delta h_{\mathrm{GDPS}-U S G S}}$ in 14 bins according to their predicted standard deviation. For each bin we take the

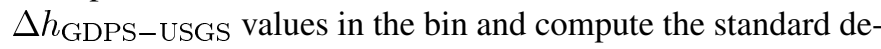
viation of the sample, which we denote the "actual" standard deviation. We plot these values versus the predicted standard 


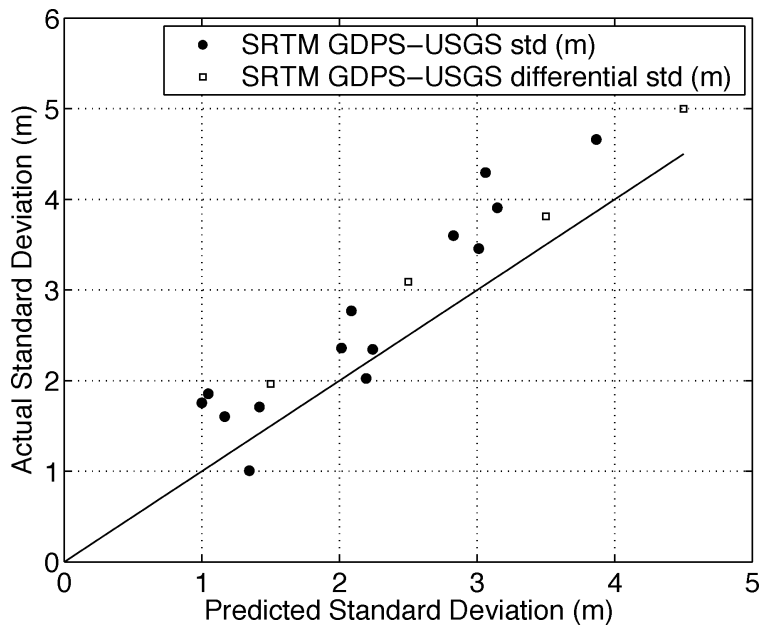

Fig. 10. Actual GDPS-USGS standard deviation versus predicted GDPS-USGS standard deviation. Actual standard deviation of difference of GDPS and USGS differentials versus predicted standard deviation of difference of GDPS and USGS differentials.

deviation (the center value of the bin). The result is Fig. 10. Observe that the points fall very close to the one-to-one line, indicating that we can estimate the actual value of $\sigma_{\Delta h_{\text {GDPS-USGS }}}$ to within about a meter using the formula above and the SRTM PI and USGS error information. This suggests that the SRTM and USGS error information is strongly correlated with the actual height errors, which is a validation of sorts of the SRTM PI and USGS error information. The approximately 1-m error in estimating $\sigma_{\triangle h_{\mathrm{GDPS}-U S G S}}$ may be due to NLCD misclassifications, which may include areas with lower interferometric coherence in our bare surface point set, thus raising the value of the "actual" standard deviation. The overall standard deviation for $\Delta h_{\text {GDPS-USGS }}$ is $2.6 \mathrm{~m}$. The mean of all the $\Delta h_{\text {GDPS-USGS }}$ points is $0.9 \mathrm{~m}$, but recall that the USGS DEMs are on average over our area $1.1 \mathrm{~m}$ higher than the GDPS, due to the mismatch in datums, so a more accurate assessment of the mean is closer to $2.0 \mathrm{~m}$. The nonzero mean of $\Delta h_{\text {GDPS-USGS }}$ is probably a result of NLCD misclassifications introducing vegetated areas in our bare surface point set. Obviously, even for bare surface areas, the SRTM GDPS data exceed the absolute and relative height error specifications.

Next, we examine the relative height error characteristics of the GDPS data for bare surface areas with the differential method, as in the case of the SRTM GDPS and the USGS DEMs for the point targets. We take the 4163 bare surface points and calculate 2780 GDPS and USGS height differentials. The pairs of points used to compute each differential are $1.5 \mathrm{~km}$ apart. We denote an arbitrary GDPS differential $\Delta h_{\mathrm{GDPS}}=\Delta h_{\mathrm{GDPS}_{2}}-\Delta h_{\mathrm{GDPS}_{1}}$ and an arbitrary USGS differential $\Delta h_{\mathrm{USGS}}=\Delta h_{\mathrm{USGS}_{2}}-\Delta h_{\mathrm{USGS}_{1}}$. Following the same reasoning as before, the standard deviation of $\Delta \Delta h=\Delta h_{\mathrm{GDPS}}-\Delta h_{\mathrm{USGS}}$ is

$$
\sigma_{\Delta \Delta h}=\sqrt{\sigma_{h_{\mathrm{GDPS}_{2}}^{2}}^{2}+\sigma_{h_{\mathrm{GDPS}}}^{2}+\sigma_{h_{\mathrm{USGS}_{2}}^{2}}^{2}+\sigma_{h_{\mathrm{USGS}_{1}}^{2}}^{2}} .
$$

We bin the $\Delta \Delta h$ values in four bins and compute the standard deviation of the sample. We plot these values versus the predicted standard deviation (the center value of the bin). The result is Fig. 10. Observe that as before in Fig. 10 the points fall very close to the one-to-one line, indicating that we can estimate the actual value of $\sigma_{\Delta \Delta h}$ using (2) to within about a meter using the formula above and the SRTM PI and USGS error information, further validating the SRTM PI and USGS error information. The mean of all $\Delta \Delta h$ is practically zero, and the overall standard deviation is $3.3 \mathrm{~m}$. As before with the absolute method, the SRTM GDPS data exceed the relative height error specifications even for bare surface areas.

\section{SUMMARY AND CONCLUSION}

We deployed a calibration array with the intention of determining the accuracy of the SRTM DEMs for southeastern Michigan. The locations in latitude, longitude, and elevation of the point targets were determined using differential GPS. We also acquired USGS DEMs to use in the calibration and validation work. We report that the SRTM PI and GDPS data for Southeastern Michigan exceed the SRTM mission specifications for absolute and relative height errors for our point target sites. In addition, the SRTM GDPS data exceed the absolute and relative height error requirements even for bare surface areas. We validated the height error files in the PI data, which are used to provide a statistical characterization of the difference between the SRTM GDPS and USGS DEM heights. The statistical characterization of the GDPS-USGS difference is of interest in forest parameter retrieval algorithms.

\section{ACKNOWLEDGMENT}

The authors are grateful to the Michigan farmers who allowed the use of their fields for this campaign. The authors are also grateful to the agriculture agents who helped locate them. Finally, the authors are indebted to the students who assisted in the campaign: D. Zahn, R. Azadegan, K. Buell, M. Casciato, P. Grajek, I. Koh, D. Lawrence, and M. Park.

\section{REFERENCES}

[1] (2002, Jul.) Shuttle Radar Topograpy Mission: The mission to map the world. [Online]. Available: www.jpl.nasa.gov/srtm

[2] R. Bamler, "The SRTM mission: A world-wide $30 \mathrm{~m}$ resolution DEM from SAR interferometry in 11 days," in Photogrammetric Week, R. Fritsch and R. Spiller, Eds, 1999, pp. 145-154.

[3] USGS. (2001, Dec.) SRTM documentation. [Online]. Available: ftp://edesgs9.cr.usgs.gov/pub/data/srtm/PI_Processor/.SRTM_Topo.txt

[4] USGS. What are these?. [Online]. Available: ftp://edcsgs9.cr.usgs.gov/ $\mathrm{pub} / \mathrm{data} / \mathrm{srtm} /$. What_are_these.txt.

[5] R. Duren, E. Wong, B. Breckenridge, S. Shaffer, C. Duncan, E. Tubbs, and P. Salomon, "Metrology, attitude, and orbit determination for spaceborne interferometric synthetic aperture radar," in Proc. SPIE AeroSense Conf. Acquisition, Tracking and Pointing XII, Apr. 1998, pp. 1-10.

[6] P. A. Rosen, S. Hensley, E. Gurrola, F. Rogez, S. Chan, J. Martin, and E. Rodriguez, "SRTM C-band topographic data quality assessments and calibration activities," in Proc. IGARSS, 2001, pp. 739-741.

[7] K. S. Rao, Y. S. Rao, and D. Jayanand, "Field experiments synchronous with SRTM flights," in Proc. IGARSS, 2001, pp. 3071-3073.

[8] K. Sarabandi, C. G. Brown, L. Pierce, D. Zahn, R. Azadegan, K. Buell, M. Casciato, I. Koh, D. Lawrence, and M. Park, "Calibration and validation of the Shuttle Radar Topography Mission height data for southeastern Michigan," in Proc. IGARSS, vol. 1, 2002, pp. 167-169.

[9] C. G. Brown, "Tree height estimation using Shuttle Radar Topography Mission and ancillary data," Ph.D. thesis, The Univ. Michigan, Ann Arbor, 2003 
[10] K. Sarabandi, L. E. Pierce, M. C. Dobson, F. T. Ulaby, J. M. Stiles, T. C. Chiu, R. De Roo, R. Hartikka, A. Zambetti, and A. Freeman, "Polarimetric calibration of SIR-C using point and distributed targets," IEEE Trans. Geosci. Remote Sens., vol. 33, no. 4, pp. 858-866, Jul. 1995.

[11] NASA/JPL-Caltech. (2004, Dec.) Shuttle Radar Topography Mission technical fact sheet. [Online]. Available: http://www2.jpl.nasa.gov/ srtm/factsheet tech.html

[12] H. Breit, N. Adam, M. Eineder, R. Bamler, and S. Suchandt, "The Shuttle Radar Topography Mission: Processing scenario and techniques," presented at the CEOS SAR Workshop, Oct. 1999. [Online]. Available: http://www.estec.esa.nl/ceos99/papers/p075.pdf.

[13] NIMA, "Department of Defense world Ggeodetic system 1984: Its definition and relationships with local geodetic systems," Nat. Imagery Mapping Agency, Bethesda, MD, Tech. Rep. TR8350.2, Jan. 2000.

[14] A. Leick, GPS Satellite Surveying. New York: Wiley, 1995, ch. 14, pp. 486-489.

[15] R. A. Snay and T. Soler, "Modern terrestrial reference systems part 2: The evolution of NAD 83," Profess. Survey., pp. 1-2, Feb. 2000.

[16] —-, "Modern terrestrial reference systems part 3: WGS 84 and ITRS," Profess. Survey., pp. 1-3, Mar. 2000.

[17] NOAA. (2002, Apr.) NGS geodetic tool kit program descriptions. [Online]. Available: http://www.ngs.noaa.gov/TOOLS/program_descriptions.html.

[18] W. A. Heiskanen and H. Moritz, Physical Geodesy. San Francisco, CA: W.H. Freeman, 1967, ch. 5, pp. 180-181

[19] NIMA. (2002, May) Geographic Translator (GEOTRANS), Version 2.2.1. Nat. Imagery Mapping Agency, Bethesda, MD. [Online]. Available: http://164.214.2.59:80/GandG/geotrans/geotrans.html

[20] D. Doyle and E. McKay. (2000, May) NGS survey marker accuracy. [Online]. Available: http://joe.mehaffey.com/ngs-accuracy.html.

[21] R. A. Snay and T. Soler, "Modern terrestrial reference systems-Part 4: Practical considerations for accurate positioning," Profess. Survey., pp. 1-3, Apr. 2000.

[22] H. A. Zebker and J. Villasenor, "Decorrelation in interferometric radar echoes," IEEE Trans. Geosci. Remote Sens., vol. 30, no. 5, pp. 950-958, Sep. 1992.

[23] R. N. Treuhaft, S. N. Madsen, M. Moghaddam, and J. J. van Zyl, "Vegetation characteristics and underlying topography from interferometric radar," Radio Sci., vol. 31, no. 6, pp. 1449-1485, November-December 1996.

[24] U.S. Dept. Interior. (2002, Jun.) National Atlas of the United States. [Online]. Available: http://www.nationalatlas.gov.

Charles G. Brown, Jr. (S'93-M'02) received the B.S. and M.S. degrees in electrical engineering from Brigham Young University, Provo, UT, and the Ph.D. degree in electrical engineering and atmospheric, oceanic, and space sciences from The University of Michigan, Ann Arbor, in 1998 and 2003, respectively.

He enjoys a variety of research areas, especially those involving electromagnetics and signal processing. He has worked at Lawrence Livermore National Laboratory, Livermore, CA, since 2003, where his work includes pulsed power system design and lightning safety studies. His previous research experience is in remote sensing of near-surface ocean wind using satellite scatterometer data and estimation of tree height using interferometric synthetic aperture radar data.

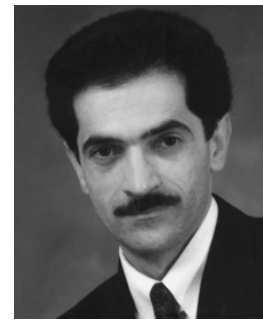

Kamal Sarabandi (S'87-M'90-SM'92-F'00) received the B.S. degree in electrical engineering from the Sharif University of Technology, Tehran, Iran, the M.S. degrees in electrical engineering and mathematics, and the Ph.D. degree in electrical engineering from The University of Michigan, Ann Arbor, in 1980, 1986, and 1989, respectively.

$\mathrm{He}$ is currently the Director of the Radiation Laboratory and a Professor in the Department of Electrical Engineering and Computer Science, The University of Michigan. His research areas of interest include microwave and millimeter-wave radar remote sensing, electromagnetic wave propagation, and antenna miniaturization. He has 20 years of experience with wave propagation in random media, communication channel modeling, microwave sensors, and radar systems and is leading a large research group including four research scientists, 12 Ph.D., and two M.S. students. Over the past ten years, he has graduated $20 \mathrm{Ph} . \mathrm{D}$. students. He has served as the Principal Investigator on many projects sponsored by NASA, JPL, ARO, ONR, ARL, NSF, DARPA, and numerous industries. He has published many book chapters and more than 115 papers in refereed journals on electromagnetic scattering, random media modeling, wave propagation, antennas, microwave measurement techniques, radar calibration, inverse scattering problems, and microwave sensors. He has also had more than 230 papers and invited presentations in many national and international conferences and symposia on similar subjects.

Dr. Sarabandi was the recipient of the prestigious Henry Russel Award from the Regent of The University of Michigan (the highest honor The University of Michigan bestows on a faculty member at the assistant or associate level) In 1999, he received a GAAC Distinguished Lecturer Award from the German Federal Ministry for Education, Science, and Technology given to about ten individuals worldwide in all areas of engineering, science, medicine, and law. He was also a recipient of a 1996 Teaching Excellence Award from the EECS Department, and 2004 Research Excellence Award from the College of Engineering of The University of Michigan. In the past several years, joint papers presented by his students at a number of symposia (IEEE AP'95, '97, '00, '01, '03 IEEE IGARSS'99, '02, IEEE MTTS'01, URSI'04) have received Student Prize Paper Awards. He is a Vice President of the IEEE Geoscience and Remote Sensing Society (GRSS), and a past Chairman of the Awards Committee of the IEEE GRSS (1998-2002) and a member of IEEE Technical Activities Board Awards Committee (2000-2002). He is serving as an Associate Editor of the IEEE TRANSACTIONS ON ANTENNAS AND PROPAGATION and the IEEE SENSORS JOURNAL. He is also a member of Commission F of URSI and of The Electromagnetic Academy. He is listed in American Men \& Women of Science Who's Who in America and Who's Who in Electromagnetics.

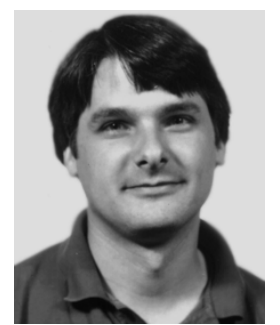

Leland E. Pierce (S'85-M'89-SM'01) received the B.S. degrees in both electrical and aerospace engineering in 1983, and the M.S. and Ph.D. degrees in electrical engineering in 1986 and 1991, respectively, all from The University of Michigan, Ann Arbor.

Since 1991, he has been the Head of the Microwave Image Processing Facility within the Radiation Laboratory, Electrical Engineering and Computer Science Department, The University of Michigan, where he is responsible for research into the uses of polarimetric SAR systems for remote sensing applications, specifically forest canopy parameter inversion. 